\title{
Active dendritic conductances enhance processing of plastic synaptic stimuli Vladislav Volman ${ }^{* 1,2}$, Herbert Levine ${ }^{1}$ and Terrence J Sejnowski ${ }^{2}$
}

\author{
Address: ${ }^{1}$ Center for Theoretical Biological Physics, University of California at San Diego, La Jolla, CA 92093, USA and ${ }^{2}$ Computational \\ Neurobiology Laboratory, The Salk Institute for Biological Studies, La Jolla, CA, 92037, USA \\ Email: Vladislav Volman* - volman@salk.edu \\ * Corresponding author
}

from Seventeenth Annual Computational Neuroscience Meeting: CNS*2008

Portland, OR, USA. 19-24 July 2008

Published: II July 2008

BMC Neuroscience 2008, 9(Suppl I):P44 doi:10.1 I86/I47I-2202-9-SI-P44

This abstract is available from: http://www.biomedcentral.com/I47I-2202/9/SI/P44

(c) 2008 Volman et al; licensee BioMed Central Ltd.

The problem of gain control in a neuron that faces thousands of synaptic stimuli has received much attention. Studies of relatively simple models established that synaptic gain can be modulated by multiple factors, such as presynaptic plasticity and/or intrinsic neuronal nonlinearities $[1,2]$. However, most central synapses are characterized by small active zones and high stochasticity of vesicular release [3]. In addition, dendritic trees abound with active conductances [4]. All of the above calls for a revised look at the simplified mean-field models of gain modulation.

Using multi-compartmental modeling techniques and a biophysically realistic model of plastic stochastic CA3CA1 synapses, we investigated here the properties of dendritic signal processing in the quantal limit of synaptic transmission. We found that, notwithstanding the relatively large number of afferent synapses, the spike trains of a model neuron are marked by quite high variability. These studies underscore the role of active dendritic conductances, and in particular of slow Ca-associated mechanisms, in the processing of plastic synaptic stimuli.

It is well-known that the mechanism of somatic spike generation in cortical neurons is very reliable. Therefore, we anticipated that the variability of output spike trains resides in sub-threshold voltage fluctuations that, in turn, reflect dendritic processing of synaptic stimuli. Indeed, making pre-synaptic short-term depression milder (by reducing the vesicle turnover time) resulted in the consistent reduction of voltage fluctuations (as captured by standard deviation), thus leading to more regular spike trains. These results corroborate previous findings on the important role of pre-synaptic depression in the control of synaptic gain [1].

In our model, the extent of spike train variability could be modulated by changing the ionic channel composition of the dendritic tree. Removal of slow mechanisms associated with calcium and calcium-activated channels led to a significant decrease of sub-threshold voltage fluctuations and to less variable output spike trains. Furthermore, a complete removal of active properties resulted in an almost regular spike train.

Distributing the synapses along the dendritic tree significantly improved the ability of a model CA1 pyramidal neuron to detect fluctuating trends in synaptic activity. The spike train of a point-like conductance-based model neuron was characterized by very low variability. By contrast, when synaptic inputs were distributed along the dendritic tree, the firing rate rose gradually for progressively increasing synaptic strength, and the typical spike train was very variable.

In summary, our studies suggest that hippocampal pyramidal cells might be equipped with mechanisms that allow them to "sense" activity-dependent trends in afferent firing. Thus, it provides a testable hypothesis as regards contextual modulation of hippocampal place cell firing. 


\section{Acknowledgements}

This research has been supported by NSF-sponsored Center for Theoretical Biological Physics (grant numbers PHY-0216576 and PHY-0225630).

Vladislav Volman has been supported by ICAM travel award.

\section{References}

I. Abbott LF, Varela JA, Sen K, Nelson SB: Synaptic depression and cortical gain control. Science 1997, 275(5297):22 I-224.

2. Prescott SA, DeKoninck Y: Gain control of firing rate by shunting inhibition: roles of synaptic noise and dendritic saturation. Proc Natl Acad Sci USA 2003, I00(4):2076-208I.

3. Dobrunz LE, Stevens CF: Heterogeneity of release probability, facilitation and depletion at central synapses. Neuron 1997, 18:995-1008.

4. Migliore M, Shepherd GM: Emerging rules for the distributions of active dendritic conductances. Nat Rev Neurosci 2002, 3:362-370.

Publish with Biomed Central and every scientist can read your work free of charge

"BioMed Central will be the most significant development for disseminating the results of biomedical research in our lifetime. "

Sir Paul Nurse, Cancer Research UK

Your research papers will be:

- available free of charge to the entire biomedical community

- peer reviewed and published immediately upon acceptance

- cited in PubMed and archived on PubMed Central

- yours - you keep the copyright 